\title{
Why Designing Is Not Experimenting: Design Methods, Epistemic Praxis and Strategies of Knowledge Acquisition in Architecture
}

\author{
Sabine Ammon ${ }^{1,2}$ (D) \\ Received: 4 October 2016 / Accepted: 26 February 2017 \\ (C) The Author(s) 2017. This article is published with open access at Springerlink.com
}

\begin{abstract}
Using the example of architecture, this article defends the thesis that designing should not be regarded as a kind of experimenting. This is in contrast to a widespread methodological claim that design processes are equivalent to experimentation processes. The contrary thesis can be proven by focusing on actual practices, techniques and design strategies. Closely connected with the thesis is an even more important epistemological claim, which contends that designing serves not only to develop artefacts but is also a means of acquiring genuine knowledge. When the epistemic relevance of said practices, techniques and strategies is reassessed, designing emerges clearly as an independent epistemic praxis. To defend the thesis, the present article draws on and analyses empirical material from an ethnographic field study in order to back up the conceptual analysis.
\end{abstract}

Keywords Designing $\cdot$ Experimenting $\cdot$ Knowledge $\cdot$ Epistemic strategies $\cdot$ Epistemology of designing $\cdot$ Architecture

\section{Introduction}

That designing is a kind of experimenting is a claim often heard in the domain of design, and it is one maintained by practitioners and theorists alike. This article considers the question of whether designing is experimenting without, however, addressing the popular metaphorical usage that highlights innovative or utopian

Sabine Ammon

ammon@tu-berlin.de

1 Institut für Berufliche Bildung und Arbeitslehre, Technische Universität Berlin, Marchstraße 23, 10587 Berlin, Germany

2 Institut für Philosophie, Technische Universität Darmstadt, Residenzschloss, 64283 Darmstadt, Germany 
approaches. Rather, it takes the claim literally in its methodological sense. A paradigmatic version of this approach is set out in the highly influential book The Reflective Practitioner by Donald Schön (1983), which revolves around the core thesis that designing - as "reflection-in-action" - relies on experimenting. For the discussion of design methods in their relation to methods in science, this stance offers a powerful and alluring fall-back position. If it can be successfully shown that methods used to design something are used equally for the purpose of experimenting, then this would bestow upon the domain of design the status of a scientific endeavour; it would prove that designing is a research activity much like those found in the natural sciences. More than this, though, this methodological claim entails an even more important epistemological one. If designing turns out to be a powerful research activity, then it must also be a means of knowledge acquisition and, hence, a domain of genuine knowledge as opposed to mere applied knowledge. It is no surprise that this issue is attracting so much attention these days. With the modification of tertiary-level curricula due to the Bologna process and the increasing pressure on academics to demonstrate research activity, disciplines characterized by designerly or artistic ways of working struggle to find academic justification and recognition for their approaches. ${ }^{1}$

My claim in this article is a different one, however. I argue that it is wrong, for methodological, ontological and epistemological reasons, to equate designing with experimenting. Indeed, it is not only wrong but also highly misleading to do so, as it weakens the legitimate epistemic claims of design. To highlight parallels between designing and experimenting is to obscure the genuine epistemic practices and strategies of knowledge acquisition involved in processes of designing. Here again, scientific methods are routinely instrumentalized as a benchmark in order to dismiss activities with other characteristics and approaches as inferior. Only if these differences are taken seriously, though (so my line of reasoning), can we start to recognize designing as an independent epistemic praxis. The rather uncommon notion of praxis serves here as an all-embracing term to incorporate habitualized practices as well as non-habitualized actions and to integrate techniques, procedures, methods and strategies into the research perspective. Analysing their epistemic relevance can explain the specific conditions of processes of learning, gaining insight and striving for epistemic progress in a particular field. Thus, by adopting a perspective that sheds light on the actual genesis of artefacts rather than just results, it becomes possible to find out whether the epistemic claim of the design domain is supported by observational evidence and whether the methodological analogy between designing and experimenting is in fact misplaced.

This latter thesis requires some clarification. I am not claiming that no experiments take place at all (they certainly do) in the field of design with its disciplines that include engineering sciences, architecture and design; nor am I arguing that design cannot also play a significant role in the natural sciences (it undoubtedly can). Rather, my approach is a heuristic one: it seeks to clarify basic concepts and provide a conceptual demarcation. By contending that it is possible to single out a specific epistemic praxis that should be called "designing" and should not-for methodological, ontological and epistemological reasons - be confused with experimenting, my aim is to provide a basis for comparison that may help us to appreciate better the "sciences of the

\footnotetext{
${ }^{1}$ Examples of recent debates on the relations between experiment, art, design and architecture can be found in Moravánszky and Kirchengast (2011), Schwarte (2011), Schwab (2014) and Buurman and Rölli (2016).
} 
artificial", as Herbert Simon (1969) put it, in relation to the realm of the natural sciences. The fact that we can find occurrences of both praxes in different disciplines - albeit to different extents - indicates some interesting interrelations and intersections between these fields.

However, a philosophical investigation of processes of designing necessarily faces a methodological challenge. Given that this article seeks to contribute to an empirical turn in the philosophy of technology (see Kroes and Meijers 2000)_by providing wellgrounded philosophical reflections on empirical material - an important question to be answered is: where are suitable and reliable sources to be found? As a praxis, designing is ephemeral. It involves experts interacting with specific procedures, techniques and tools. Although we find physical manifestations of (interim) results - such as sketches, drawings, descriptions, working models and prototypes - most of them will not be archived but ultimately thrown away as by-products of an ongoing process: they gradually lose their value as the design evolves further. Therefore, any approach that works with retrospective or historical case studies (as are prevalent in the philosophy of science) is confronted with serious problems because most of the material needed to analyse the case thoroughly no longer exists. As a consequence, historical analysis generally struggles with meagre sources when it comes to manifestations of processes, making it an even more speculative undertaking to draw conclusions about actual practices from these findings. In contrast, detailed descriptions of methods and procedures are found in the literature of design methodology. The advantage of such standard literature is that it is usually written by people working in the field and is based on studies by "insiders". However, another problem lurks here too. This body of literature is not primarily descriptive but rather has prescriptive intent (see, e.g. Ehrlenspiel 2009, Lindemann 2009, Müller 1990, Pahl et al. 2007). It seeks to improve existing design processes by introducing specific methods, idealized procedures and a standardization of design phases. Hence, given that engineers, architects and designers are often reported to be very reluctant to adopt the proposed methods, little can be said about how close these descriptions are to actual design processes. ${ }^{2}$

Yet in the last decade, an alternative has emerged. In a new body of literature, we find an increasing number of studies analysing actual design processes using ethnographic methods. These studies have emerged from cultural anthropology, microsociology, science and technology studies and linguistics and aim to give an inside view of design methods and practices. They continue and refine the path set out by Schön in The Reflective Practitioner - a book which can also be seen as an early work that uses ethnographic methods to achieve a better understanding of the praxis of designing. Therefore, my investigation also indirectly addresses the question of whether ethnographic investigation can serve as an empirical basis for further developing a philosophy of design and, if so, how it can shed light on whether or not designing is a kind of experimenting. I do so by discussing a case study conducted by Albena Yaneva in which she presents a detailed analysis of an architectural design project. This study draws crucially on actor-network theory (ANT), which was initially used to investigate scientists and their habitual practices in the laboratory by ethnographic means, in order to work out the material basis of such disciplines (see, e.g. Latour and Woolgar 1979,

\footnotetext{
${ }^{2}$ See, e.g. Müller (1990, p. 1); Cross (2006, p. 96). A detailed discussion of descriptive and prescriptive aspects in John Gero's approach can be found in an analysis by Pieter Vermaas and Kees Dorst (2007).
} 
Lynch 1985, Knorr-Cetina 1981, 1999). This approach has recently been extended to the engineering sciences, architecture and design. In this way, methods originally developed to study peoples and cultures have now been transferred to document and decipher processes of creation.

In order to resolve the issue of whether designing is a kind of experimenting, the field of architecture can be regarded as a paradigm case. This is not only because, as Schön puts it, architecture is "perhaps the oldest recognized design profession and, as such, functions as prototype for design in other professions" (Schön 1983, p. 77). It is also because it offers some methodological advantages compared to other areas of design when it is a matter of finding out more about actual design techniques, procedures and practices. The size of project teams in architecture is moderate and therefore easier to keep track of - even considering the external experts who participate in them - than many large projects in engineering. Compared to single person projects, however, it demands specific structures of communication which make the design processes more accessible to outside observers. In addition, the working processes are less based on the division and specialization of labour than in engineering, thus making it possible to maintain a focus on the overall design process. Furthermore, elaborate forms of notation and specific tools for reflection have evolved in the field of architecture to enhance the creative process, resulting in tangible manifestations of this very design process. A disadvantage could be the duration of a project, which can last several years. This poses a problem for studies aimed at considering the development of a project as a whole. However, since only certain design practices need to be analysed to elucidate the main question addressed by this article, project duration need not hinder us here. For these reasons, then, the analysis and discussion of design processes in architecture can offer valuable insights and can complement existing investigations in the philosophy of design. ${ }^{3}$

\section{Designing: a Kind of Experimenting?}

An influential account of designing as experimenting, as mentioned in Section 1, can be found in Schön's The Reflective Practitioner. Schön characterizes designing "as a conversation with the materials of a situation" (Schön 1983, p. 78) which "[i]n a good process of design [...] is reflective" (ibid, p. 79). The designer is making a move in the design process that causes changes. By this, the situation "talks back" (ibid.), provoking a response by the designer to the situation's back-talk. Schön calls this reaction reflection-in-action: "In answer to the situation's back-talk, the designer reflects-inaction on the construction of the problem, the strategies of action, or the model of the phenomena, which have been implicit in his moves" (ibid, p. 79). In the course of the design process, the designer is "spinning out a web of moves, consequences, implications, appreciations, and further moves" (ibid, p. 94). Schön addresses each move as a local experiment when, for example, variations of a certain geometrical shape are tried out. In their turn, local experiments are embedded in a global experiment of "reframing

\footnotetext{
${ }^{3}$ So far, existing investigations in the philosophy of design have focused primarily on specific areas of engineering. A rare example, which includes both engineering and architecture, is Vermaas et al. (2008); see also Banse et al. (2006), Kornwachs (2007, 2010).
} 
the problem" (ibid) which sets the direction for the inquiry. Both of these are a reflective conversation with the situation (ibid, p. 94f.) - a shared "generic process" (ibid, p. 78) that underlies the various design cultures in architecture. ${ }^{4}$

What reasons does Schön give for designating the individual design move and the comprehensive reframing of the problem as an experiment? In a nutshell, he claims that changes prompted by a design move are often unintended and unexpected. Part of Schön's answer is anchored in his notion of the design situation. For Schön, designing is a complex process which he explains as follows: "There are more variables - kinds of possible moves, norms, and interrelationships of these - than can be represented in a finite model" (ibid, p. 79). Although this description could be questioned-for it does not differentiate between variables and parameters on the one hand and combinations and interrelations on the other, all of which need not be infinite - it confirms a common characterization of designing as being an elusive form of problem-solving: "The situation is complex and uncertain, and there is a problem in finding the problem" (ibid, p. 129). In the literature of design research, the latter issue is also addressed as the co-evolution of design and solution (see, e.g. Maher 2000); the former relates to the famous characterization by Horst Rittel and Melvin Webber of design problems as "wicked problems", "whereas science has developed to deal with 'tame' problems" (Rittel and Webber 1973, p. 155).

Schön investigates the design process from a praxis perspective; he is interested in the effects of this complexity not at the level of a system's analysis but at the level of concrete design practices. From this point of view, "the practice problem is a unique case" (Schön 1983, p. 129). The individual design moves are unpredictable and result in surprising outcomes for the designer who has to interpret and evaluate the findings. ${ }^{5}$ As a consequence, sometimes moves are "resisted" when, for example, a set of design stipulations does not work; sometimes moves engender "new phenomena", when, for example, unforeseen spatial potentials are discovered in a constellation (ibid, p. 94). These findings from the local experiment call for "new appreciations" (ibid) and guide the subsequent moves in the design process. If the "whole idea" (ibid, p. 95) is questioned and, for example, a new approach needs to be found in order to reconcile the shape of the building with the affordances of the site, then according to Schön a global experiment is taking place. In order to find a new solution, the existing problem must be reframed by developing a new overall idea, whose implications must also be scrutinized.

When discussing whether designing is a kind experimenting, it is important to make a differentiation between a broad and a narrow sense of experiment. Nowadays, a broad sense of experiment, one closely related to the Latin notion of experimentum as attempt, test or trial, is quite common. In this context, it is used to indicate activities that have an

\footnotetext{
${ }^{4}$ However, Schön's interest in The Reflective Practitioner goes beyond architecture. "Reflection-in-action", according to his theory, is intrinsic not only to the design disciplines but to professional practices in general, be it town planning, engineering, psychotherapy or management, all of which he investigates in separate case studies.

${ }^{5}$ It is important to note here that there are significant differences between a beginner or learner and a trained professional. The latter "zeroes in immediately on fundamental schemes and decisions which quickly acquire the status of commitments. He compresses and perhaps masks the process by which designers learn from iterations of moves which lead them to reappreciate, reinvent, and redraw. [...] He does not need to play out all of the trees of moves which might follow from his initial reframing of the problem" (Schön 1983, p. 104).
} 
open-ended outcome or to describe inquiring into something that might be innovative or more risky than usual. Understood in this way, it would be hard to deny that designing is equivalent to experimenting - and indeed because of its broadness, this understanding is of no help in clarifying the putative epistemic difference between the two praxes. So what is emphasized here instead is the narrow notion of experiment as a method elaborated within science, one of the "[p]rocedures for attaining scientific knowledge" (Hatfield 1998). Usually, experimenting as a "rule-governed scientific method" (Röseberg 1990, p. 977, translated by the author) is differentiated from that of formulating theories and from observation and pure measurement. By means of active experimental interventions, dependencies and interrelations can be explored with the help of common standards of measurement and calibrated measuring devices. With the introduction of the experiment, scientific effort is no longer confined to pure descriptions of nature but rather opens up to the discovery of general laws that describe the structure of conditions and allow prediction and manipulation (cf. Hatfield 1998, Röseberg 1990, pp. 977 ff.). This leads to a characterization of the experiment in methodological, ontological and epistemological terms, as pointed out by Wenceslao Gonzalez (2007, p. 278): the experiment is a repeatable process associated with "reproducibility and replicability"; it is related to the idea of "otherness", and it stands for the production of "reliable" knowledge "through a non-immediate process".

With his notions of local and global experiment, Schön is addressing not just the broad notion of experiment; his claim is more far-reaching. For him, the praxis of designing also meets the demands of the narrow notion of experiment; the same "rigour in on-the-spot experiment" (Schön 1983, p. 133, comp. 145) found in scientific research can be found in design. In order to substantiate his claim, he heuristically differentiates between three kinds of experiment found in both design and science. Exploratory experiments are actions performed in order to see what happens, without being embedded in predictions or expectations. "Exploratory experiment is the probing, playful activity by which we get a feel for things. It succeeds when it leads to the discovery of something there" (ibid, p. 145). Move testing experiments are actions performed in order to achieve an intended change. "Any deliberate action undertaken with an end in mind is, in this sense, an experiment" (ibid, p. 146). In its simplest structure, the initiating move is affirmed if the outcome corresponds to the intended consequences; if it does not, the move is negated. However, as moves often also produce unintended effects, Schön proposes a more general reading: "Do you like what you get from the action, taking its consequences as a whole? If you do, then the move is affirmed. If you do not, it is negated" (ibid). Hypothesis testing experiments are actions aimed at discriminating among competing hypotheses found implicitly in the pattern of the moves. "If, for a given hypothesis, its predicted consequences fit what is observed, and the predictions derived from alternative hypotheses conflict with observation, then we can say that the first hypothesis has been confirmed and the others, disconfirmed" (ibid, p. 146). The hypotheses are discriminated "within the limits of the constraining features of the practice context [...] - taking as disconfirmation of a hypothesis the failure to get the consequences predicted from it" (ibid, p. 147). According to Schön, it is specific to the context of design that experiments performed by the practitioner in his reflection-in-action are exploratory, move testing and hypothesis testing experiments all at the same time - in contrast to scientists who distinguish between these different kinds of experiment (ibid, p. 147). 
On the surface, Schön's claim is backed by studies in the history and the philosophy of science on the praxis of experimenting. ${ }^{6}$ With regard to epistemological and methodological questions, many statements sound familiar when looking at methods, epistemic practices and strategies of knowledge acquisition in processes of designing. Without being able to follow this line of investigation here in detail, a few examples may serve to give an idea of this. For example, Margaret Morrison (1998) highlights "validating procedures" and "constraints for evaluating results" and investigates "the credibility of particular instruments" within their operativity; Timothy Lenoir characterizes experimenting as explorations of alternatives with an open ending (Lenoir 1992, p. 186, referencing Frederic L. Holmes) just as Schön points to practices of exploration within designing (see, e.g. Schön 1983, pp. 153, 156, 166); Hans-Jörg Rheinberger emphasizes the importance of iterations in processes of experimenting as well as the adeptness of the experimenter (Rheinberger 2005, pp $58 \mathrm{ff}$.) — this is echoed in Schön's formulations that stress the "iterations of moves" (Schön 1983, p. 104) and the "virtuosity" (ibid.) of the designer's performance.

When actual praxis is investigated, we find that a number of striking parallels exist between designing and experimenting, such as rigorous inquiry, iterative exploration, unintended and unexpected results, a progressive honing of questions and a gradual approach towards solutions. But do these findings prove that designing is indeed a kind of experimenting? No. It was John Dewey who long ago pointed out that when the praxis becomes epistemically relevant, we are confronted with similarities - regardless of whether we are talking about the natural sciences, engineering or medicine. He pointed out that "there is no way in which the procedures used by the competent engineer or physician in solving problems of determination of singular cases logically differ from the procedures used by another group of men in establishing generalizations" (Dewey 1938, p. 438). The parallels indicated by Schön describe the creative, active and craftsman-like elements that constitute processes of searching and probing, trying and testing in the search for insight. Variations of these kinds of exploration can be found in any epistemic praxis regardless of whether we calculate, interpret, argue, experiment or design. Hence, what Schön describes as "exploratory experiments" are nothing other than the exploratory nature of activities found in epistemic praxes in general. The same goes for Schön's broad definition of "move testing experiments", which frames any purposeful probing as experimenting. Given this, Schön's study provides strong arguments for defending the thesis that designing is indeed an epistemic praxis, a bundle of practices, tools and techniques that enable genuine knowledge to be generated. What is not yet demonstrated, though, is that the two epistemic praxes of designing and experimenting belong to the same category - if one wants to hold the much stronger thesis that designing is indeed a kind of experimenting. However, a decisive answer can only be found by looking close-up at design practices and analysing them in terms of epistemology and methodology. Schön's investigation

\footnotetext{
${ }^{6}$ Since the 1980 s, it is the movement of experimentalism within the history and philosophy of science that has drawn attention to the actual praxis of the experiment. As Theodore Arabatzis points out, it "reflects a promising shift from an exclusive philosophical preoccupation with the end products of scientific activity to a systematic investigation of that activity itself. This shift has led to a novel view of science. Science, on this view, is not simply a changing body of knowledge, codified in textbooks and research papers, but an evolving array of practices" (Arabatzis 2008, p. 168). For further examples, see also the case studies in Hans Radder (2003).
} 
concentrates only on the teaching situation, which has the advantage that the actors explicate in their conversation many otherwise implicit design moves; the disadvantage of this, however, is that it documents the learning process of a 'novice' rather than professional design practices. In what follows, therefore, I propose to shift the empirical basis. To discuss and illustrate the thesis of this article, I examine a case study that offers a meticulous account of an actual project as it develops in an architectural bureau.

\section{Considering Scale: Albena Yaneva's Case Study at OMA}

"[T]o understand what the designers do when they conceive a building" (Yaneva 2005, p. 868) - this is the aim of a study by Albena Yaneva that I wish to discuss more thoroughly in the following pages. ${ }^{7}$ The study, influenced by actor-network theory and especially by the work of Bruno Latour, is one of a number of recent studies on architectural practices in the field of science and technology studies (STS) and has shed light especially on the relevance of scaling. Yaneva "lives" (ibid), as she calls it in an allusion to ethnographic field work, in the Office for Metropolitan Architecture (OMA) or, more precisely, in the unit of a project team responsible for the extension of the Whitney Museum of American Art in New York. The company, co-founded by Rem Koolhaas in 1979, is one of the most renowned architectural bureaus in the world, having developed many acclaimed projects such as Casa da Música in Porto, the embassy of the Netherlands in Berlin and CCTV Headquarters in Beijing.

When OMA was commissioned to design the extension of the Whitney Museum of American Art, the building already had a long history (Yaneva 2009, pp. 8-20, 203204). Shortly after its completion in 1966, the building, designed by Marcel Breuer and Hamilton Smith (Fig. 1), was bursting at the seams. In 1979, Derek Walker Associates and Foster Associates were called upon to find a solution to enlarge the existing building, followed by Michael Graves who, between 1981 and 1989, developed three controversial variations that remained unbuilt. After a hiatus, OMA tried between 2001 and 2004 to convince the clients to develop a novel approach (Figs. 2 and 3). To anticipate the outcome: this suggestion too was rejected due to the high costs it would involve. Shortly after this, Renzo Piano was chosen to solve the problem; the new building finally opened at a different location in 2015.

Conceiving a museum involves bringing together and harmonizing a whole host of different requirements. Generally, the building should act as an urban landmark; the rooms need to be suitable for displaying artworks; the arrangement of the rooms needs to ensure that visitors are guided through the exhibition; and lighting, statics, building physics and the constraints of fire prevention laws all have a considerable impact on the design. ${ }^{8}$ The clichéd design process proceeds from preliminary, rough, small-scale considerations to fully developed, large-scale details. In practice, however, many overlaps take place. Yaneva observes, for example, that there is a discussion about the cubature of the building in relation to the surrounding area and about the specific

\footnotetext{
${ }^{7}$ In the following, I draw on the description provided in Yaneva (2005). Where necessary, this description is supplemented with information found in Yaneva (2009). A detailed discussion of Yaneva's approach within the context of actor-network theory has been published in Ammon (2012).

${ }^{8}$ This is just a fraction of the requirements; see also Yaneva (2005, p. 872).
} 


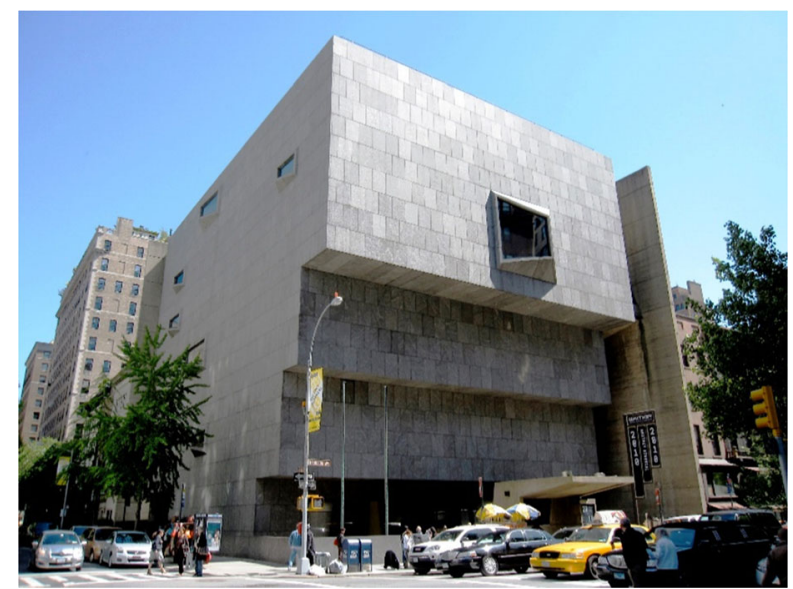

Fig. 1 Home of the Whitney Museum of American Art, designed by Marcel Breuer and Hamilton Smith, from 1966 to 2014.@ Gryffindor 2010, https://commons.wikimedia.org/wiki/File:Whitney_Museum_of_ American_Art.JPG, accessed 15 August 2016

usage of the space going on at the same time. As a result, the design proceeds by working simultaneously on models in different scales (Fig. 4). For Yaneva, this shifting of scales turns out to be a core technique for developing the building, "a building that is made knowable and real as scales are shifted” (Yaneva 2005, p. 868). She concludes:

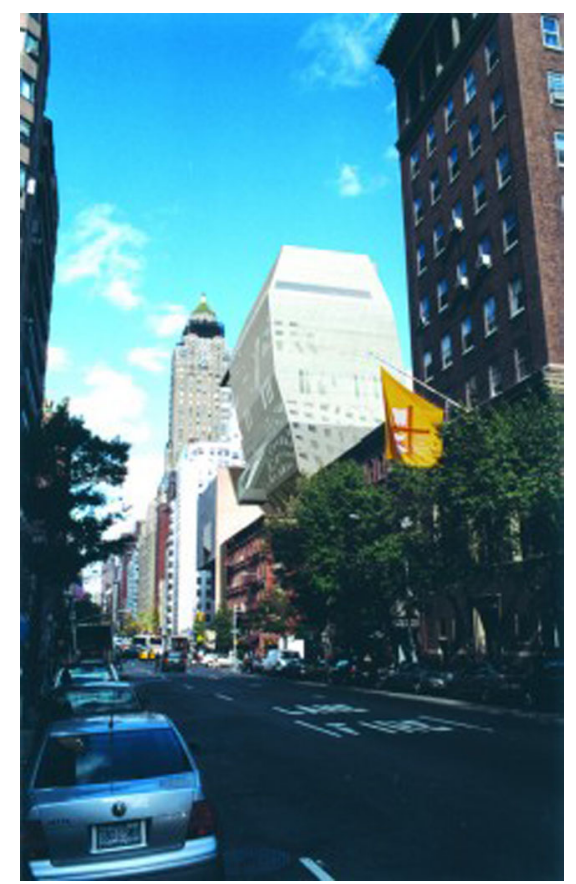

Fig. 2 Collage showing the extension of Whitney Museum of Modern Art in New York in a street perspective. (C) OMA 


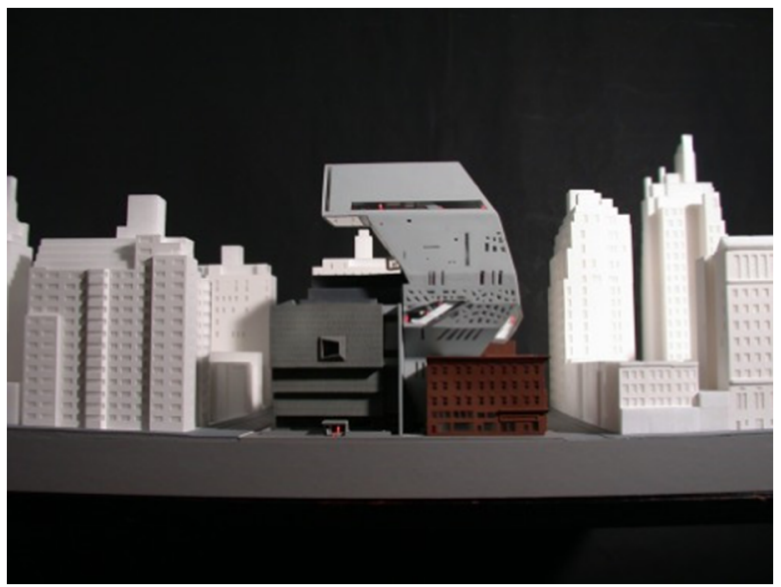

Fig. 3 Model of the Whitney Museum extension. (C) OMA

"Through such practices, a building can be conceived in thought and brought into existence" (ibid, p. 869).

Pivotal to the core issue addressed in this article is that Yaneva, without making it explicit, refers back to the classification by Schön and interprets scaling in design processes as an experimental situation: "[I]t is subjected to constant and well-equipped observation of possible consequences of acting on scale models; it is an apparatus for conducting, recording and interpreting the results of manipulating selected features of models" (ibid, p. 868). These design experiments are characterized by the fact that the architects either scale up or down in order to scrutinize the consequences of these actions. Yaneva identifies two kinds of experiments: the exploratory move that involves "probing in trial-and-error fashion" (ibid) and the systematic test that "[aims] for an intended outcome to be confirmed or disconfirmed. These tests aim at probing parameters and realities connected to the building's particular mission" (ibid, p. 868f.). However, neither of these candidates can count as a classification of experiments. Exploration, as we have seen earlier, is not a distinctive feature of experimenting but rather a common feature of any epistemic praxis. Testing, which is prevalent in the engineering sciences, is structurally different from experimenting and cannot count as a

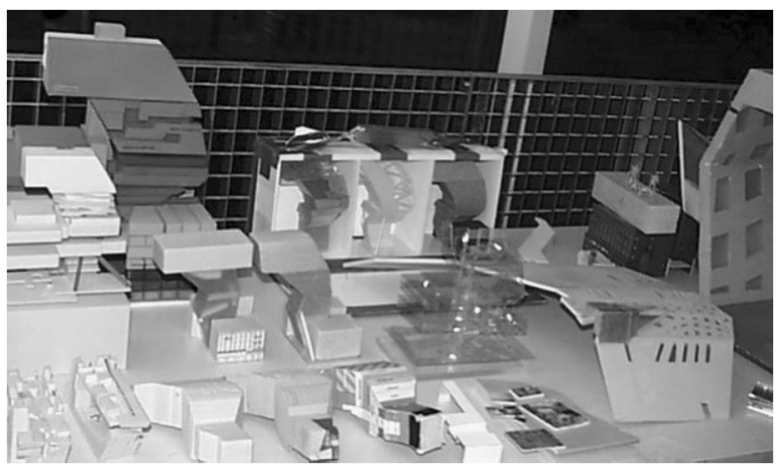

Fig. 4 A collection of working models at different scales. (C) Albena Yaneva 
kind of experimenting (Kornwachs 2012, pp. 123-128). Testing is intrinsically linked to prototyping or scale modelling in order to scrutinize a specific scenario. From the point of view of a logical reconstruction (a stance which Kornwachs takes), we find a deductive-nomological inference in the case of the experiment and a practical syllogism in the case of the test. Or, to put it more bluntly: we are dealing with laws when we experiment, and we are dealing with rules when we test. In contrast to an experiment, a test does not explore whether a certain effect can be subsumed under a law but rather explores whether a rule is effective. Hence, tests with scale models in architecture are not instances of experimenting. Again, as with Schön, the theoretical framework and the resulting interpretation provided by the author do not support the claim of designing being experimenting. ${ }^{9}$

Still, even if Yaneva's theoretical analysis does not hold in this respect, it could be the case that the practices of scaling she describes actually are instances of experimenting. Let us therefore follow Yaneva in a detailed description of a typical instance of scaling. At a certain stage of the design, the position of an escalator causes major problems and has to be moved. Kunlé, an architect, rearranges the escalator in the large spatial model which shows not only the building infrastructure but also art works and visitors (Fig. 5). Unsure with the outcome, he asks his fellow team members whether they like the proposal. They encourage him to "scope" the new arrangement. Kunlé now turns to the smaller model with a tiny paper escalator and rigorously investigates the space enclosed by walls made of cardboard. One observation tool used in this scaling practice - a "modelscope"- has an important function: it is a specific kind of endoscope that makes it possible to get a visual impression of the interior of the model; thanks to this tool, even small-scale models can convey an inside view of a building (Fig. 6). In order to explore the effect of possible positions, the modelscope is used by the design team to check the new placement. The individually performed investigations are commented on and evaluated in the group; a joint search for new ideas and changes takes place (Fig. 7). With this analysis at hand, the group returns to the large model in order to perform a number of modifications. The models, being at the core of the scaling practice, trigger discussions and, with their help, the design is reworked and developed further. They serve as "important tools for shared cognition" (ibid, p. 872), as Yaneva describes it: "[A]rchitects think of the building by modelling, by cutting foam and paper and using various scoping techniques. It is not a free intuitive creation of a building shape generated 'out of the blue"' (ibid, p. 872).

For Yaneva, the larger scales do have "a larger scope, with greater cognitive and representational power" (ibid, p. 882) due to "their distinct capacity to capture heterogeneous actors in a model” (ibid, p. 881). "[T]he large scale model is more powerful, not because of an inherent superiority of size, but because it has the ability to capture more parameters and concerns, to sum up more requirements and limitations, to reflect

\footnotetext{
${ }^{9}$ A different view was put forward by the sociologist Trevor Pinch (1993) who argued that testing is the common ground in experimenting and in designing technology. However, although testing - which is used to examine in depth a specific stage of the project by considering certain questions - can be part of an experimental setup as well as of a design setup, this does not strengthen the argument that experimenting and designing are structurally the same. Pinch's argument merely indicates that a more precise heuristic differentiation is needed between the epistemic praxes of experimenting, testing and designing; this would make it possible to judge better to what extent the elements of one praxis enter another and how their mutual relations unfold.
} 


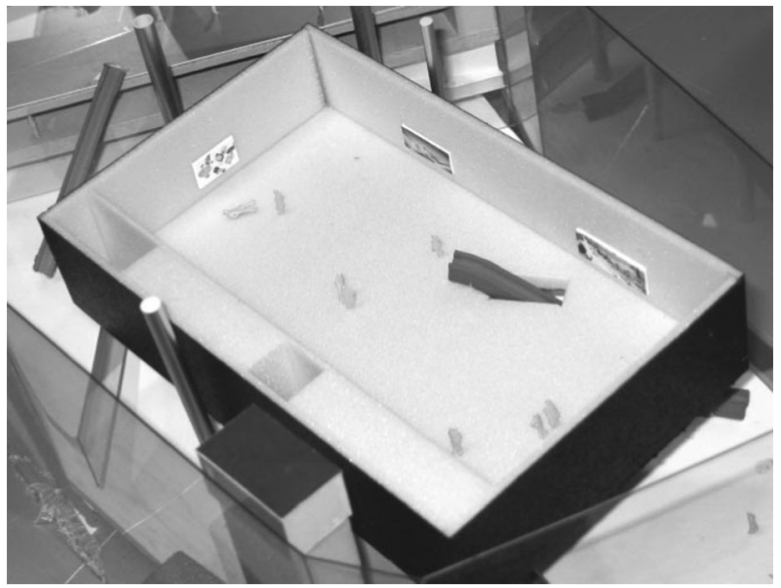

Fig. 5 Scale model exploring the interior space. (C) Albena Yaneva

more details, corners and finishing, to enrol more viewers, to enable more bodies to gather around it, to mobilize the public awareness better, to provoke more violent disputes or to trigger more unpredictable actions" (ibid). Small and large models stand for "abstract" versus "concrete" or "inquiry and speculation" versus "practical concerns" (ibid, p. 885). Therefore, the small- and the large-scale models correspond, according to Yaneva, to the states of "knowing less" and "knowing more" (ibid, p. 881). The knowledge in question is a "knowledge about shapes, dispositions, locations; again, this is not knowledge of facts, but rather knowledge about spatial transitions, not 'knowing that', but 'knowing where'" (ibid, p. 885). In their working, both small- and large-scale models interact in a "circuit" (ibid, p. 886): "[W] hen the small model is no longer needed because its job has been completed, it is scaled up and transformed into a large one; when the large model accomplishes its function, it is necessary to return to the small one" (ibid). The scaling procedures refine the building and render it "more and more visible, more present, more material, real" (ibid, p. 887). Recurring processes of sizing up and down continue until a stabilization is achieved. ${ }^{10}$

Despite Yaneva's neglect of the role of paper-based work in relation to model building (giving rise to a one-sided view of scaling tools and techniques), her examples convincingly show that knowledge about what is being designed is gradually acquired within the process, and she is right to claim that this sort of knowledge cannot be adequately grasped solely by "knowing that". However, her epistemological interpretation of the findings appears to be over-simplified from a philosophical point of view. To address this knowledge as "knowing where" is not satisfying, since design knowledge comprises much more than just spatial relations; also, simply coupling the states of "knowing more" or "knowing less" to scale is incorrect, as scale relates to different sets of problems. It is therefore time to turn away from Yaneva's account and to ask the general question of whether ethnographical investigations are suitable for a more philosophically precise description of design processes in architecture. Yaneva calls her approach an "ethnographical observation" (Yaneva 2005, p. 888, footnote 1). Correspondingly, we find in the methods and sources employed throughout the

\footnotetext{
${ }^{10}$ See also (ibid, p. 883, 887f.); in exceptional cases, greater shifts in scale also take place (see ibid., pp. 882 f.).
} 


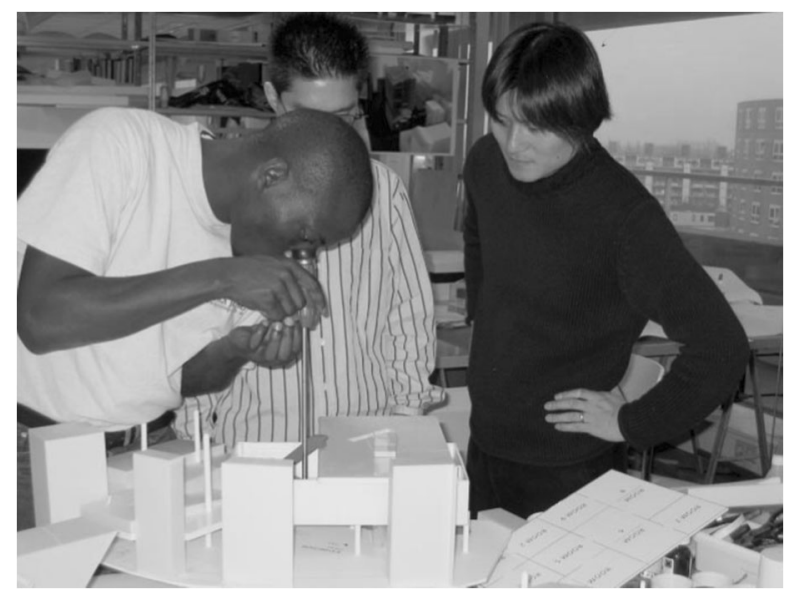

Fig. 6 Examining the model using a modelscope. (C) Albena Yaneva

investigation some basic elements of field research, including participant observation. In anthropology, participant observation enables the researcher to be involved in dayto-day activities over a long period of time; it allows her to work with the language of the field and to study anything that happens in its quotidian context (see Salzmann

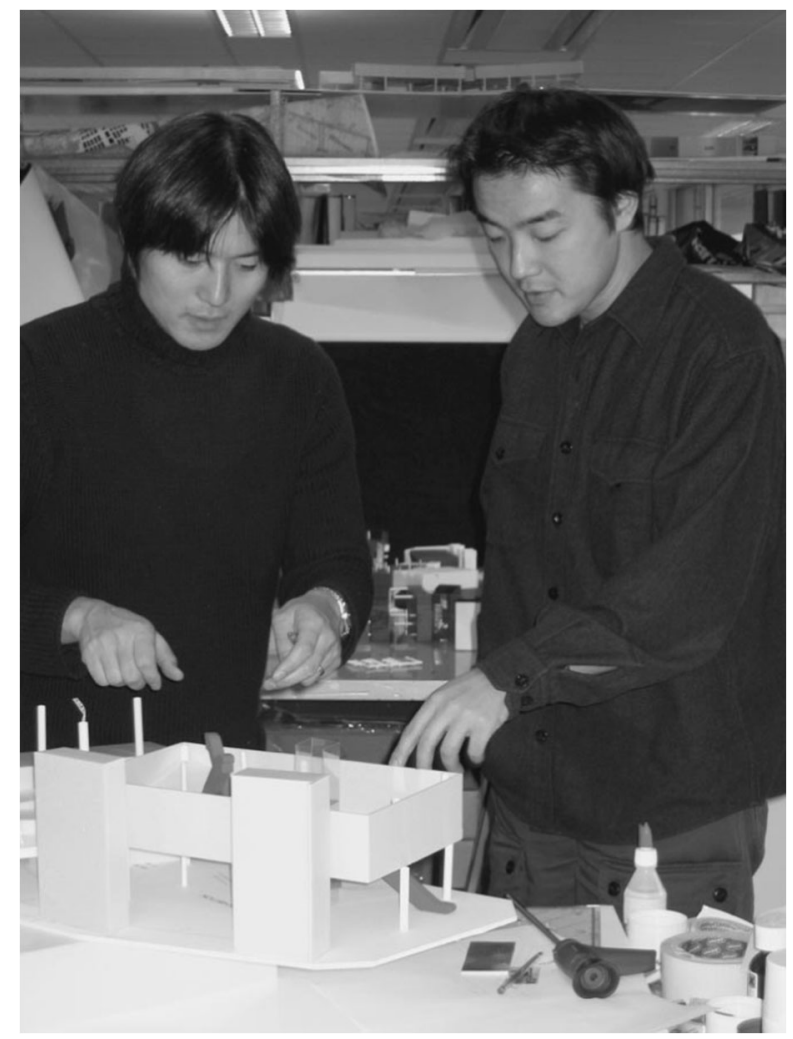

Fig. 7 Team discussion of the findings supported by the model. (C) Albena Yaneva 
2010). Adopting this stance, Yaneva occupies a place at the project team's table. By doing so, she acquires an inside view of the processes and is able to follow technical discussions, operations and presentations, habits and rites; she takes notes, photographs and sound recordings. These observations are supplemented by in-depth interviews with the people involved in the projects, by archival studies, and by a training in the field that consisted of "learning specific architectural terms, of mastering the design vocabulary and trying to cope with the realities of the office in the same way [... as the architects] did" (Yaneva 2009, p. 35). In the end, as Yaneva puts it, she "began, up to a certain point, to think and act like an architect" (ibid). ${ }^{11}$

A number of fundamental constraints associated with ethnographic approaches to design processes in architecture are conspicuous here. For one thing, the period of investigation is usually short compared to the entire design process: design (including planning) processes can last for many years, especially when big and complex projects are in question, such as that of developing a museum. Ethnographic studies often rely on 6 months of field research accompanied by intensive periods of preparation and post-processing before and after the field stay. ${ }^{12}$ As a consequence, only specific stages of the design process are analysed. Yaneva starts her field research when early variants of the design are already worked out and a larger project team has already been put together; she conducts her observations at the conceptual design stage $(2009$, p. 10 , footnote 12). At this stage, however, a significant number of the decisions central to the design have already been taken on two levels at least: in a preparatory dialogue with the clients in order to outline and articulate in more detail their intentions for the project, in a thorough examination of the site and by compiling variations of preliminary design and at a bureaucratic or administrative level by outlining planning restrictions. After the planning approval stage, the permit set evolves into the construction plans, which turn into the construction process where changes in the design still take place. Usually, at the beginning of a larger project, only a few people are involved. The team is augmented by a range of external experts linked to the project when the planning process begins. As a consequence, the communication structure and working materials change throughout the different stages of the design process; conversation, sketches, scale models, drawings, descriptions and images can have different functions depending on the stage in which they are introduced or occur. This becomes apparent only when the whole process of designing (including planning and constructing) is considered-something which would require an observation period of several years. ${ }^{13}$

Another constraint is that, in Yaneva's case, only one architectural bureau-and within the bureau, only one team - is subjected to field research, as the data collection is very time-consuming. However, the praxis of designing has many different schools and traditions: quite apart from the question of style, many design cultures exist and are manifested, for example, in their preferences for computers or pencil

\footnotetext{
${ }^{11}$ For a description of the sources, see Yaneva (2009, pp. 23-35) and Yaneva (2005, p. 869).

12 This time span can be found, for example, in Murphy (2004, 2005) and Ewenstein and Whyte (2007, 2009); Ignacio Farías even uses a much shorter time span of one and a half months (2013, p. 84). However, Yaneva's period of investigation is longer; she returns over a period of 2 years to the office whenever new developments in the project take place (Yaneva 2005, p. 888, Yaneva 2009, p. 34).

${ }^{13}$ For an insight into professional everyday practice, see, e.g. Cuff (1992) and Grubbauer and Steets (2014).
} 
and sketchpad, for modelling or drawing, for modes of collaboration and communication and so on. This is not only a personal choice: methods and techniques also depend on education and training, on the degree of routine and on the demands and complexity of the task at hand.

One might assume that this leads to a problem when generalizing the study's findings. Whether or not the constraints mentioned above will actually turn into a problem, however, depends on the nature of the conclusions we want to draw from a set of ethnographical observations. For example, statements about the design process as a whole based on findings derived within a limited period of time would be questionable. This is quite apart from the fact that only one stage of the design process is focused on during the observation period and that the stages of a design process can differ significantly with regard to the factors influencing them, the working procedures adopted and the composition of the design team. Similarly, it would be questionable to claim that the design culture observed within this one design team is typical of all other design processes. However, the intended impact of Yaneva's study is a different one. Her aim is to single out scaling, a technique easily overlooked, as an important element in the advancement of design processes and their related modes of knowledge acquisition. That scaling is indeed an important technique is confirmed by a range of design curricula, textbooks and professional guidelines. By embedding her study in the state of the art of the research literature, she renders plausible the notion that her investigation does not involve outlier practices and deviations or exceptional circumstances and that her findings are not a mere product of her research method. Hence, her assertion that scaling is an important and general knowledge practice in architecture is indeed well grounded. ${ }^{14}$

Nevertheless, the question remains to what extent a study like Yaneva's can contribute to a philosophical analysis on the epistemology of designing. It is the deployment of "anthropology's commitment to depth and thick description" (Candea 2010, p. 486) in those ethnographical investigations that enables valuable access to the praxis perspective, with its insights into methods, techniques and practices. Such insights could not be gained in the studio situation involving a student and an instructor or in psychological experiments in the laboratory or through mere quantitative inquiry. Findings of this kind can be used as telling examples to empirically ground a general line of argument regarding the nature and epistemology of designing. In this way, ethnographic fieldwork offers a rich repository of actual instances of design which help to paint a more "realistic" picture. Hence, in the following I will use the scaling techniques described by Yaneva as a touchstone for investigating the philosophical claim that designing is a kind of experimenting.

\footnotetext{
${ }^{14}$ An apparent asymmetry in reasoning can also be used to expose common design myths such as the napkin sketch, in which a design is created in a single intuitive moment, on the basis of a ready-made image formed in the mind. The scaling procedure becomes a telling example that reveals this design myth by falsification (see Popper [1935] 1994, p. 7); the underlying structure of reasoning is the modus tollens. However, generalizing on the basis of a single outcome is considered a fallacy, and inductive inferences require stronger corroborations.
} 


\section{Methodological, Ontological and Epistemological Differences}

In order to explore the relationship of designing and experimenting in more detail, let us return to the characterization put forward by Gonzalez. He defines the practice of experimenting according to seven aspects, three of which matter for the present discussion (Gonzalez 2007, p. 278): methodologically, "experiment is connected to a process which should be repeatable and, therefore, it is commonly associated to the reproducibility and replicability"; ontologically, "experiment is related to the idea of otherness (i.e. something — real or not—which is used to test)"; and epistemologically, "experiment is related to a kind of reliable knowledge acquired through a nonimmediate process. ${ }^{\prime 15}$ Drawing on Yaneva's observations about scaling, I seek to show in the following that in all three aspects highlighted by Gonzalez there is indeed a crucial difference between designing and experimenting.

Let us begin, first, with the methodological difference. According to Gonzalez, experimenting is associated with repeatability. Its aim is to elicit the same results under similar conditions; technical devices and tools serve as stabilizing factors to guarantee this effect. In science, an important proof of the truth of empirical findings is the confirmation of the results by a different research team. Successful reproducibility is seen as a methodological virtue and a necessity; any malfunction relating to reproducibility and replicability is seen as a defect which needs to be either eliminated or explained as an anomaly. In designing, the situation is entirely different. It would be highly implausible for the same outcome to be achieved by a different team of architects under similar conditions - any such outcome would immediately be classified as plagiarism. ${ }^{16}$ The very different design proposals put forward by Michael Graves, OMA and Renzo Piano for the Whitney Museum extension give an idea of just how different architectural design outcomes can be (though in this case the situation is more complicated, as the requirements changed throughout the process). The peculiarity of designing becomes more obvious when we consider the diversity of results in a studio crit or a competition based on the same design task. Superficially, we might think that style and aesthetic preference are responsible for this effect; a suspicion which, at first glance, seems to be confirmed in the case of large, prestigious projects in which the creators seek to be recognizable in the product. However, the key reason for this effect is rather that designs need to be tailored to a particular solution: they are subject to specific constraints which have to do with complex framework conditions such as costs, materials and intended use. The consequence is a blurred design situation, countless potential parameters and a variety of possible optimal solutions, all of which lead together to the vast variety of outcomes. The reasons for this can be found in the open-endedness that characterizes the start of a design process; this is often

\footnotetext{
${ }^{15}$ For the sake of completeness, the remaining aspects should be mentioned here as well: semantically, "experiment originally has a sense and a reference that differs from 'observation", logically, "experiment is a structural ingredient of science which is different from 'theory' and, in principle, it is also distinct from "model'", axiologically, "the experiments can be oriented through different values according to distinct aims (i.e. experiments in basic science could be divers from experiments in applied science)", ethically, "there is concern on some kinds of experiments, mainly when they are related to certain human affairs (either to the persons as individuals or to the society as a whole)" (Gonzalez 2007, p. 278).

${ }^{16}$ The detailed analysis of design and construction processes in the aviation industry by Walter Vincenti (1990), which confirms the great variety of (potential) results, suggests that the situation in the engineering sciences is rather similar.
} 
referred to as "fuzziness" (cf. Banse 2000, p. 66 f., translated by the author) or "wickedness" (cf. Rittel and Webber 1973). There is a need to explicate the aims of the design process within the design process itself, in a so-called co-evolution of design and solution (e.g. Maher 2000). The construction of many working models at different scales (Fig. 4) is precisely what supports this endeavour and leads to the harmonization of often conflicting demands, aims and conditions. A dependency on fuzzy processes of evaluating and weighting that incorporate particular preferences and values leads to specific results - and hence to singular insights. General insights and generalizable principles are to be found on another level and are often passed on as non-explicit know-how. This explains the characteristic lack of repeatability in design, which constitutes a methodological virtue; it must not be confused with the lack of repeatability in science, which is reported as methodological failure. ${ }^{17}$

Second, there is an ontological difference. The project analysed by Yaneva shared the fate of many endeavours in the design disciplines: after many years of intensive planning by OMA, the project of extending the Whitney Museum of Modern Art on the Upper East Side was called off. Designing is projective; it aims to develop future procedures or artefacts. During the crucial phases of their evolution, the design seeks to make manifest something which is non-existent and which might never exist, as in the case of the OMA design. Herein lies a fundamental difference in contrast to experimenting: Experimenting as a method used in the natural sciences (in its narrow sense, described above) is geared towards real-world phenomena. In contrast to this, designing has no such "counterpart". As Gonzalez put it in his definition, there is no "idea of otherness" (2007, p. 278) or pre-established design "goal" during the decisive phases of development. In ontological terms, designing explores the non-existent (or not yet existing) world whereas experimenting explores the existing world. ${ }^{18}$

This ontological difference becomes clearer when it is reformulated in terms of modes of reference. Figure 1 above shows a building on the Upper East Side in New York which hosted the Whitney Museum of Modern Art from 1966 to 2014 and was designed by Marcel Breuer and Hamilton Smith. As a photograph, it refers to (or denotes) the building and is hence called a depiction. We get a similar result in terms of reference when we turn to Fig. 2: the photograph documents the presentation model of the Whitney Museum extension; it refers to the model and is hence a depiction.

\footnotetext{
${ }^{17}$ This difference in methodological virtues explains why failures in repeatability, which happen again and again, do not support the argument that experimenting and designing are methodologically the same. The same goes for argumentation and persuasion: although some positions in the sociology of technology (e.g. Latour and Woolgar 1979, Knorr-Cetina 1981, Collins 1985, Pinch 1986) have shown that these techniques play a role in experimenting which should not be neglected, again, this does not support the claim that experimenting and designing are methodologically the same. The same goes for the so-called experimenters' regress, an argument developed by Harry Collins (1985, pp. 79-111). Collins contends that what is usually taken by scientists as a good experimental result is obtained by a good (properly functioning) experimental setup. At the same time, the goodness of an experimental setup is judged by the fact that it gives good results - and hence, according to Collins, there are no formal criteria to decide whether the setup is working properly. Even if Collins' claim were justified (which is highly contested, see, e.g. Franklin and Perovic 2015), the fundamental methodological difference remains due to the different methodological virtues.

${ }^{18}$ As indicated by the philosopher of technology Hans Poser, this difference is an achievement of the modern age and is shown in the opposing notions of discovering (German: ent-decken) and creating (German: entwerfen). The older Latin term invenire incorporates both meanings (Poser 2013, p. 137 f.). Interestingly, positions based on strong constructivism obliterate this differentiation by exaggerating the creational and manmade aspects.
} 
However, the situation differs fundamentally when we start to analyse the mode of reference of the scale model itself. The model components in light and dark grey as well as those rendered in brown show the new building complex including the refurbishment of the Breuer Building and the brownstones. As a whole, the model refers to "nothing" - as the envisioned artefact does not exist. ${ }^{19}$ In his investigation of the modes of reference of notations, Nelson Goodman called these occurrences "null denotation" (1968, p. 21 ff.). In terms of reference, then, we have an extraordinary situation: during the crucial planning stages, all the design models (along with all the sketches, drawings, plans, renderings, calculations and descriptions) refer-while they are used as tools of reflection - to nothing. They are exclusively instances of null denotation. $^{20}$

In some cases, though by no means all, the design will ultimately be realized. Then, a model or plan which has served up to that point as a design tool turns into an instruction manual. Oliver Scholz explained this feature in the context of image theory by highlighting the different intentions attached to depictions and "design images" (2009; 2012). According to Scholz, they vary in their "direction of fit" (Scholz 2012, p. 48): in the case of the former, the image is made to fit the world, while in the case of the latter, the world is made to fit the image. Hence, depictions can be described by a mindto-world directedness and "design images" by a world-to-mind directedness. However, after the design has actually been built, a technical drawing or model can turn into a depiction: at this point, it is documenting the produced artefact - just as the photograph in figure one documents the Whitney Museum of Modern Art.

As a consequence, only in its very late phases does the design process enable an iterative adaptation to real world phenomena-when the artefact is actually built. However, during the major part of the process of designing, no actual realization of that which is invented is available for adjustment or correction. ${ }^{21}$ In contrast to an experimental situation where worldly phenomena are at our disposal as working materials throughout the entire process, in the decisive phases of exploration in designing the working materials are restricted exclusively to "proxies", which do not represent in any literal sense. Designing is characterized by what we might call phase displacement: in architecture, the reality check takes place afterwards, once the building has been constructed and is in use. In contrast to experimenting, which relies on empirical validation within the exploration process, the empirical validation in designing only takes place when it comes to construction and usage-and thus after the exploration process has been terminated and the basic design has been developed and

\footnotetext{
${ }^{19}$ When the individual components of the model are analysed, the situation becomes more complex. The white model components refer to the existing surroundings (and are therefore depictions), whereas all the other components show a future scenario which includes a comprehensive conversion of the Breuer building and the brownstones.

${ }^{20}$ Design here shows interesting parallels to fiction-however, with an important difference to mere fiction as found in literature or the visual arts. In successful processes of designing, null denotation is limited in time because of the subsequent realization; becoming a "real" artefact is intended right from the beginning. Exceptions are visionary and fantasy architecture which usually lack this intention. They nevertheless refer to the general framework set by ordinary design.

${ }^{21}$ This diagnosis holds true even if mock-ups are considered. Especially for major projects partial 1:1 mockups (e.g. a façade model) became a quite familiar tool for examining specific problems (e.g. special construction details or material selection, without embedding them in the related systems of heating and airconditioning).
} 
approved. Although the insights gained in the process of realization and usage do not support the ongoing design process, they can nonetheless be of relevance for future developments. This factor might explain why experience is of such crucial importance in the design professions.

We now come, third, to the epistemological difference between designing and experimenting. As was convincingly shown by Yaneva, and by Schön before her, epistemic exploration takes place during the design process. It is through this process that insights are approved and knowledge stabilized. This in turn ensures that, when it comes to realization and usage, the design works and fits - in architecture as well as in engineering. Whether or not the static system of a bridge will collapse due to certain vibrations should not be left to be discovered during the construction phase; the ability of a mobile phone to transfer voice signals despite high winds and loud background noise must be guaranteed before manufacture; and it is crucial to find out prior to an emergency whether the braking distance of a train remains constant even in different operating conditions.

Yet if there are no worldly phenomena to explicate, how can we reasonably argue that knowledge about the future artefact is acquired in the design process? Traditional epistemology points to the concept of truth when it comes to explaining the nature of knowledge. Experimenting is about discovering true findings which are backed up by empirical facts and are, as Gonzalez writes, "acquired through a non-immediate process" (2007, p. 278). However, as one of the core elements of any traditional definition of knowledge, truth does not help in the case of designing. Even our ordinary use of language marks the difference: whereas the statement that the law of gravity is true is a classical scientific claim, the statement that a building (or a sewage system, a gas turbine, or a car) is true would not be classified as a scientific claim but as ideology. As an epistemic endeavour, designing does not seek to discover truth; instead, it strives for rightness. If we want to describe outcomes that fit and work in an epistemic sense so that they therefore constitute consolidated knowledge, we would say the building was designed correctly, that is, it exhibits rightness. However, the notion of rightness does not simply portray a result; rather, it shifts the focus onto the process of its origination: the design process itself comes to the fore.

Rightness was introduced as an epistemological concept by Catherine Elgin and Nelson Goodman (Goodman 1978; Goodman and Elgin 1988; Elgin 1996, 2006; cf. Ammon 2009, 2016). Applied to the domain of architecture, it enables us to get a better grasp on the epistemology of designing. In the context of a procedural epistemology, Elgin and Goodman frame rightness as a dynamic process of equilibration which makes it possible to describe epistemic gains and progress independently of "external" factors of approval in the manner of a "god's eye view". Little by little, in hard-won steps and iterative loops, rightness is developed, options are checked countless times, revised, discarded or improved until, eventually, reliable knowledge emerges in a stabilized form which allows for the realization of the artefact. Many factors may have an impact on ensuring this outcome. They may pose constraints, establish frameworks or simply guide the direction of the ongoing process. To give some examples: When exploring the design problem, selecting from among variations or assessing potential results, several factors can be of major importance, such as the coherence of the design, its conformity with well-established bodies of knowledge, the relevance of certain parameters, the anchoring of partial results in existing design experience, the range of the 
intended solution and the effects on the overall setting. To support the design process, it is possible to fall back on approved and, in some cases, standardized knowledge corpora which are fed into the ongoing process and are developed further by it. Some of this knowledge is found in manuals, norms, regulations or laws (which are often influenced by socio-political interests), and some elements derive from different disciplinary knowledge domains. Whether these factors play a role depends on the context and the situation at hand. The effects and consequences of the overall structure need to be considered when solving problems, favouring applications, eliminating anomalies, making differentiations and establishing relations.

This specific epistemic constellation explains why proxy materials play such a prominent role throughout the process of designing. These design artefacts - in Schön's words "the materials of a situation" (Schön 1983, p. 78) — are the one and only material resource at hand that enables the projected design, and hence the design knowledge, to be probed and explored. There are sketches, drawings, plans, perspectival renderings, diagrams, tables, different kinds of models, numerical-based calculations and descriptions in verbal language-just to mention the most striking ones (see, e.g. Elser and Cachola Schmal 2012, Ammon and Capdevila Werning 2017). In their notational structure, they open up milieus of reflection which help to develop the design further and to convey (partial) results; in doing so, they serve as "thinking" tools and as media of communication. Notations are certainly an important aid to thinking, reasoning and communicating - in many other epistemic praxes, experimenting included. However, it is the aspect of exclusiveness which is so characteristic of the design disciplines. Due to the ontological situation and the projective nature of design, only the notational exploratory setup is able to provide answers; there is no outside authority that might serve as a neutral judge. For an epistemology of designing, this presents itself as a riddle: depending on the situation, the outcome seems to be fairly arbitrary. Anything goes; the result depends, apparently, on the will of its creator.

The answer to this riddle lies in the techniques and methods which make it possible to continually check the evolving design. Used in combination with particular tools and design artefacts, these practices help designers to implement epistemic strategies, that is, endeavours that actively pursue epistemic objectives and are an integral part of epistemic praxes in general. This also allows us to reframe the practice of scaling, which was presented by Yaneva - erroneously - as an experimental situation (see above). Scaling is a specific technique that is used to implement and support epistemic strategies in design processes, as shown in the following examples:

- Reducing complexity: This often goes hand in hand with parsing sub-issues and identifying unresolved questions and is done by narrowing down missing information and lacunae and filling gaps where possible. The reduction of complexity can successfully be supported by scaling. Enlargement or sizing down enables us to concentrate on certain aspects. For example, in building design, we often find the scales 1:1000 and 1:500 used to focus on urban aspects, 1:200 and 1:100 for answering questions regarding approval planning, 1:50 for execution planning and $1: 20,1: 10$ or $1: 5$ for construction details. If the change of scales is skilfully doneas Yaneva describes in the case study - then it is possible to work on partial problems and to clarify dependencies and interrelations. 
- Varying and comparing: This can take place at various stages of the design using several techniques and media. It is often found in the individual process of sketching, when tracing and copying techniques are used with transparent sketching paper to explore the changes and their consequences on specific aspects. It can also be found in an abundance of working models, as in Yaneva's example. Highlighting differences by means of comparison is often done in meetings by juxtaposing different drawings or models (or both). Again, scale can support this strategy: comparison is facilitated by working within a fixed scale. ${ }^{22}$

- Identifying relevant parameters: In the design process, scenarios are played through and modified in order to get an overview of possible consequences which, in turn, need to be critically evaluated. This requires the relevant parameters to be identified and isolated before being tested, with the aim of revealing interrelations. In this way, many factors that have a major impact on the design task in question come into view. It is possible to explore the extent to which they are negotiable and changeable and also to check out how they need to be weighted according to their relevance in cases of conflict. A shifting of scales can support this search, as described in the case of the escalator in Yaneva's study. In particular, the small scale indicates the effects of the escalator's position for the building's circulation while the large scale gives an impression of the concrete spatial situation. By analysing their interdependencies, the influencing parameters can be singled out.

- Assessing: The process of exploration described by Yaneva is closely related to the development of assessment criteria for choosing appropriately from among variants. The criteria make it possible to give reasons for preferences and to set priorities. In determining a suitable position for the escalator, criteria had to be developed by the team to judge the different options available. ${ }^{23}$

- Externalizing and explicating: Designing relies very much on this strategy in order to make moves that are often only implicitly comprehensible. This is usually done with the help of notational techniques: an important element of plans is the scale indicated in the legend, which leads to specific rules of depiction. Depending on whether the plan's scale is 1:500, 1:100 or 1:50, not only what is depicted differs but also how it is depicted (Bielefeld 2014) — which in turn enables us to address different questions.

- Searching for errors: Projecting techniques are helpful here as well as a mutual matching process of elevations, sections and floor plans, as they enable a planner to cross-check connections and interdependencies. The same goes for model-building techniques: shifting the scale can enhance this process. Increasingly, the search for errors is also supported by software: new building information modelling (BIM)

\footnotetext{
${ }^{22}$ A vivid sketching example can be found in an investigation by Boris Ewenstein and Jennifer Whyte (2007, p. 699, Fig. 2). That these procedures of variation and comparison can also be conducted verbally is shown by the analysis of a design team meeting by Keith Murphy (2004). Grouped around a table covered by the current floor plan of the envisioned object, the team starts to develop several variations for a possible solution concerning a particular design problem. By intentionally bringing together differing standpoints based on differing expertise and personal background, prior decisions are recapitulated, conflicting demands are worked out and priorities are set. This can be done in a small team of three — as in the case study by Murphy —or in a larger meeting including external experts, clients, authorities or the public: by deliberately encouraging plurality and dissonance, it is possible to push forward the search for a solution.

${ }^{23}$ A preliminary discussion of design criteria in architecture from a philosophical point of view is offered by Pitt (2008).
} 
programs can implement an automated 'clash detection' (Borrmann et al. 2015, pp. 272-277, 281-282, Eastmann et al. 2011, pp. 272-275).

Contrary to the impression one might get from Yaneva's investigation, scaling is not the only technique but one among a number of techniques and methods - each with their particular usage of tools and media - to be found in processes of designing. Other candidates include practices of sketching, drawing, projecting, modelling and calculating. Many of them are interrelated; usually, there is a variety at hand from which the designer can choose to support the same process. Not only personal preferences but also the demands of the project-geometrically complex forms, for example, will require different methods than a design based on regular patterns - lead to differing cultures of designing. The variety, however, also has epistemic reasons. On the one hand, every milieu of reflection - with its specific forms of notation, techniques, media and related epistemic strategies - provides an arena in which to address selected features and aspects of a design. This explains why so many different techniques and methods with their respective tools and materials are employed in the design process, as they complement each other when addressing design problems in different ways. However, they not only complement each other, they also make it possible to crosscheck the results. If similar results are acquired through different milieus of reflection, the insights gained are strengthened and lead towards stabilized knowledge. In addition, this diversity also explains why the design can neither be reduced to any specific notational product or to the sum of all of them. The design artefacts always and only convey specific features and aspects, and not all relevant features and aspects can be conveyed by design artefacts in any case. Knowledge based on experience as well as many non-notational forms of instruction are needed to successfully complete the construction phase of a building. ${ }^{24}$

\section{Conclusion}

The case study by Yaneva vividly presents the technique of scaling as a valuable means of knowledge generation and, hence, as a mode of genuine knowledge production. The case of scaling shows how, in the design process, the search for insights and knowledge is promoted by specific techniques, methods and strategies. These help to single out problems, identify unresolved questions, supply procedures for tentative solutions as well as to refine and check them until they convincingly withstand scrutiny. The shift in scale exemplifies how unresolved aspects are approached in a multi-modal manner and how tireless critical questioning and trying out of provisional outcomes takes place

\footnotetext{
${ }^{24}$ A note needs to be added here. Characterizing the technique of scaling and the use of scale models as important elements in the design process does not imply that they are employed exclusively in the design process. Indeed, the opposite is the case. The technique of scaling might also become part of experimental or testing situations, and scale models can occur both as "models of the world" and as "models as step in design" (Müller 2009, p. 642 ff., p. 646 ff.), that is, as design models and depicting models (Ammon 2017). Hence, the mere occurrence of scaling techniques or of scale models is neither an indicator of the epistemic praxis of designing nor does the use of scale models necessarily lead to the methodological, ontological and epistemological differences discussed above. Whether or not these differences actually occur can only be revealed by a more comprehensive analysis of the epistemic praxis itself.
} 
until a stable result is achieved or an unsuccessful one abandoned. Scaling serves here as a placeholder for the impressive variety of techniques, tools and materials. In close interrelation, they enable processes of iteration and variation, of weighing and selection, of searching and sounding out, thereby enabling, throughout, the careful development and conscientious analysis of the future artefact.

The previous section has shown that the differences between designing and experimenting run deep when methodological, ontological and epistemological issues are taken into consideration. The analysis of these issues clearly leads us to assert that designing is an independent and effective epistemic praxis as important as experimenting, interpreting, reasoning or calculating. Moreover, due to the similarities that exist within the broader design domain, one can assume that this finding applies not just to the field of architecture but also to engineering design, as well as to any area where artefacts are conceived. At this point, one might be tempted to ask to what extent the analysis of a specific design technique such as scaling allows us to draw conclusions regarding the epistemic praxis of designing in general. Whether we are considering sketching, drawing, projecting or modelling, the very same methodological, ontological and epistemological issues arise as long as they serve as means to explore that which as yet is non-existent. However, they differ in the range of questions they are able to address and in their validation strategies. This is where future research needs to begin. The exact role of differing milieus of reflection in these areas needs to be determined; to do so, the empirical basis needs to be broadened. An interesting parallel to simulation also arises here, where we have many instances of null denotation, as described earlier. This might be a hint that, in some cases and in certain respects, simulation-based exploration is closer to designing than to experimenting - a line of thinking which provides a promising approach for engaging in the ongoing debate about whether or not simulation is a kind of experimenting (e.g. Winsberg 2015, Schiaffonati 2016 for simulation in engineering science).

So far, the present analysis has shown that designing is a genuine epistemic praxis rather than a kind of experimenting. However, the analysis has not demonstrated something which the thesis of designing as experimenting often also implies: it has not shown that designing correlates to a scholarly method or even that it stands for scientificity in general. Indeed, by characterizing designing as an epistemic praxis, the question regarding its scientificity is not even posed. Although genuine knowledge production in the design domain can reasonably be argued for, the path from designing as an epistemic praxis to "design science" — or the "science of design" - has not yet been trodden. ${ }^{25}$ Results from design processes can certainly serve as a source and primary material and, hence, can flow into further scholarly work on, for example, meta-analyses, comparative structural investigations or the reworking of procedural rules. In this way, results enter into systematized processes which engender knowledge that goes beyond singular cases and which is usually not spelled out in the ordinary design process. However, in order to transfer insights deriving from a design process into a systematized explicit body of knowledge, a reflexive moment must come into

\footnotetext{
${ }^{25}$ Nigel Cross (2006, p. 97 ff.) distinguishes between scientific design which "refers to modern, industrialized design based on scientific knowledge", design science which "refers to an explicitly organized, rational and wholly systematic approach to design" and science of design which "refers to that body of work which attempts to improve our understanding of design through 'scientific' (i.e. systematic, reliable) methods of investigation".
} 
play, a moment that methodically checks, evaluates and organizes underlying processes. This kind of design research already differs from the original activity of designing in its critical distancing, systematization and generalization as well as in its practices of transmission and dissemination of results, all of which are embedded in scientific work. As soon as these aspects come into play, then the praxis in question is no longer the epistemic praxis of designing but is part of a comprehensive science of design.

Acknowledgements This research received support from the European Union on the basis of a Marie Skłodowska-Curie Fellowship (Grant Agreement no. 600209, project IPODI).

Open Access This article is distributed under the terms of the Creative Commons Attribution 4.0 International License (http://creativecommons.org/licenses/by/4.0/), which permits unrestricted use, distribution, and reproduction in any medium, provided you give appropriate credit to the original author(s) and the source, provide a link to the Creative Commons license, and indicate if changes were made.

\section{References}

Ammon, S. (2009). Wissen verstehen: Perspektiven einer prozessualen Theorie der Erkenntnis. Weilerswist: Velbrück Wissenschaft.

Ammon, S. (2012). ANT im Architekturbüro. Eine philosophische Metaanalyse. Zeitschrift für Ästhetik und Allgemeine Kunstwissenschaft, 57(1), 127-149.

Ammon, S. (2016). Explaining understanding, understanding knowledge. In S. Grimm, C. Baumberger, S. Ammon (Eds.), Explaining understanding: New perspectives from epistemology and philosophy of science (pp. 92-110). Routledge.

Ammon, S. (2017). Epilogue: The rise of images in the age of modeling. In S. Ammon \& R. Capdevila Werning (Eds.), The active image: Architecture and engineering in the age of modeling. Springer, forthcoming.

Ammon, S., \& Capdevila Werning, R. (Eds.). (2017). The active image: Architecture and engineering in the age of modeling. Springer, forthcoming.

Arabatzis, T. (2008). Experiment. In S. Psillos \& M. Curd (Eds.), The Routledge companion to philosophy of science (pp. 159-170). London: Routledge.

Banse, G. (2000). Konstruieren im Spannungsfeld: Kunst, Wissenschaft oder beides? Historisches und Systematisches. In G. Banse \& K. Friedrich (Eds.), Konstruieren zwischen Kunst und Wissenschaft: Idee - Entwurf - Gestaltung (pp. 19-79). Berlin: edition sigma.

Banse, G., Grunwald, A., König, W., \& Ropohl, G. (2006). Erkennen und Gestalten: Eine Theorie der Technikwissenschaften. Berlin: edition sigma.

Bielefeld, B. (2014). Architekturdarstellung. Basel: Birkhäuser.

Borrmann, A., König, M., Koch, C., \& Beetz, J. (Eds.). (2015). Building Information Modeling. Technologische Grundlagen und industrielle Praxis. Wiesbaden: Springer Vieweg.

Buurmann, G., \& Rölli, M. (2016). Die Eigenlogik des Designs. Zürich: Zürcher Hochschule der Künste, Departement Design.

Candea, M. (2010). Multi-sited ethnography. In A. Barnard \& J. Spencer (Eds.), The Routledge encyclopedia of social and cultural anthropology (pp. 485-486). London: Routledge.

Collins, H. M. (1985). Changing order: replication and induction in scientific practice. London: Sage Publisher.

Cross, N. (2006). Designerly ways of knowing. London: Springer.

Cuff, D. (1992). Architecture: the story of practice. Cambridge: MIT Press 2. print.

Dewey, J. (1938). Logic: the theory of inquiry. New York: Holt, Rinehart and Winston.

Eastman, C., Teicholz, P., Sacks, R., \& Liston, K. (2011). BIM handbook: a guide to building information modeling for owners, managers, designers, engineers, and contractors. Hoboken: Wiley.

Ehrlenspiel, K. (2009). Integrierte Produktentwicklung: Denkabläufe, Methodeneinsatz, Zusammenarbeit. München: Hanser.

Elgin, C. Z. (1996). Considered judgment. Princeton: Princeton University Press.

Elgin, C. Z. (2006). From knowledge to understanding. In S. Hetherington (Ed.), Epistemology futures (pp. 199-215). Oxford: Oxford University Press. 
Elser, O., \& Cachola Schmal, P. (Eds.). (2012). Das Architekturmodell: Werkzeug, Fetisch, kleine Utopie/The architectural model. Tool, fetish, small utopia. Zurich: Scheidegger \& Spiess.

Ewenstein, B., \& Whyte, J. (2007). Beyond words: aesthetic knowledge and knowing in organizations. Organization Studies, 28(5), 689-708.

Ewenstein, B., \& Whyte, J. (2009). Knowledge practices in design: the role of visual representations as 'epistemic objects'. Organization Studies, 30(1), 7-30.

Farías, I. (2013). Epistemische Dissonanz. Zur Vervielfältigung von Entwurfsalternativen in der Architektur. In S. Ammon \& E. M. Froschauer (Eds.), Wissenschaft Entwerfen: Vom forschenden Entwerfen zur Entwurfsforschung der Architektur (pp. 77-107). München: Wilhelm Fink Verlag.

Franklin, A., \& Perovic, S. (2015). Experiment in physics. In E. N. Zalta (Ed.), The Stanford encyclopedia of philosophy (Summer 2015 Edition). http://plato.stanford.edu/archives/sum2015/entries/physicsexperiment. Accessed 26 August 2016.

Gonzalez, W. J. (2007). The role of experiments in the social sciences: the case of economics. In T. A. F. Kuipers (Ed.), General philosophy of science: focal issues (pp. 275-301). Amsterdam: Elsevier.

Goodman, N. (1968). Languages of art. An approach to a theory of symbols. Indianapolis: Bobbs-Merrill.

Goodman, N. (1978). Ways of worldmaking. Indianapolis: Hackett.

Goodman, N., \& Elgin, C. Z. (1988). Reconceptions in philosophy and other arts and sciences. Indianapolis: Hackett.

Grubbauer, M., \& Steets, S. (Eds. 2014). The making of architects: knowledge production and legitimation in education and professional practice. Architectural Theory Review 19(1).

Hatfield, G. (1998). Scientific method. In E. Craig (Ed.), Routledge encyclopedia of philosophy. London: Routledge. http://www.rep.routledge.com/article/Q093. Accessed 26 November 2013.

Knorr-Cetina, K. (1981). The manufacture of knowledge: an essay on the constructivist and contextual nature of science. Oxford: Pergamon Press.

Knorr-Cetina, K. (1999). Epistemic cultures: how the sciences make knowledge. Cambridge: Harvard Univ. Press.

Kornwachs, K. (Ed.). (2007). Bedingungen und Triebkräfte technologischer Innovationen. Stuttgart: Fraunhofer IRB Verlag.

Kornwachs, K. (Ed.). (2010). Technologisches Wissen: Entstehung, Methoden, Strukturen. Berlin: Springer.

Kornwachs, K. (2012). Strukturen technologischen Wissens: Analytische Studien zu einer Wissenschaftstheorie der Technik. Berlin: edition sigma.

Kroes, P., \& Meijers, A. (Eds.). (2000). The empirical turn in the philosophy of technology. Amsterdam: JAI.

Latour, B., \& Woolgar, S. (1979). Laboratory life: the social construction of scientific facts. Beverly Hills: Sage Publications.

Lenoir, T. (1992). Praxis, Vernunft und Kontext: Der Dialog zwischen Theorie und Experiment. In T. Lenoir (Ed.), Politik im Tempel der Wissenschaft: Forschung und Machtausübung im deutschen Kaiserreich (pp. 172-208). Frankfurt a. M: Campus.

Lindemann, U. (2009). Methodische Entwicklung technischer Produkte: Methoden flexibel und situationsgerecht anwenden. Berlin: Springer.

Lynch, M. (1985). Discipline and the material form of images: an analysis of scientific visibility. Social Studies of Science, 15, 37-66.

Maher, M. L. (2000). A model of co-evolutionary design. Engineering with Computers, 16, 195-208.

Moravánszky, Á., \& Kirchengast, A. (Eds.). (2011). Experiments: Architektur zwischen Wissenschaft und Kunst. Berlin: Jovis.

Morrison, M. C. (1998). Experiment. In E. Craig (Ed.), Routledge encyclopedia of philosophy. London: Routledge. http://www.rep.routledge.com/article/Q033SECT3. Accessed 26 November 2013.

Müller, J. (1990). Arbeitsmethoden der Technikwissenschaften: Systematik, Heuristik, Kreativität. Berlin: Springer.

Müller, R. (2009). The notion of a model: a historical overview. In A. Meijers (Ed.), Philosophy of technology and engineering sciences, handbook of the philosophy of science (Vol. 9, pp. 637-664). Amsterdam: Elsevier.

Murphy, K. M. (2004). Imagination as joint activity: the case of architectural interaction. Mind, Culture, and Activity, 11(4), 267-278.

Murphy, K. M. (2005). Collaborative imagining: the interactive use of gestures, talk, and graphic representation in architectural practice. Semiotica, 156-1(4), 113-145.

Pahl, G., Beitz, W., Feldhusen, J., \& Grote, K.-H. (2007). Konstruktionslehre: Grundlagen erfolgreicher Produktentwicklung, Methoden und Anwendung. Berlin: Springer.

Pinch, T. (1986). Confronting nature: the sociology of solar-neutrino detection. Dordrecht: Reidel.

Pinch, T. (1993). "Testing — one, two, three, ... testing!": toward a sociology of testing. Science, Technology, and Human Values, 18(1), 25-41.

Pitt, J. (2008). Design criteria in architecture. In P. E. Vermaas, P. Kroes, A. Light, \& S. A. Moore (Eds.), Philosophy and design: from engineering to architecture (pp. 317-327). Dordrecht: Springer.

Popper, K. ([1935] 1994). Logik der Forschung. Tübingen: Mohr. 
Poser, H. (2013). Ars inveniendi heute: Perspektiven einer Entwurfswissenschaft der Architektur. In S. Ammon \& E. M. Froschauer (Eds.), Wissenschaft Entwerfen: Vom forschenden Entwerfen zur Entwurfsforschung der Architektur (pp. 135-166). München: Fink.

Radder, H. (Ed.). (2003). The philosophy of scientific experimentation. Pittsburgh: University of Pittsburgh Press.

Rheinberger, H.-J. (2005). Iterationen. Berlin: Merve Verlag.

Rittel, H. W. J., \& Webber, M. M. (1973). Dilemmas in a general theory of planning. Policy Sciences, 4, 155169.

Röseberg, U. (1990). Experiment. In H. J. Sandkühler (Ed.), Europäische Enzyklopädie zu Philosophie und Wissenschaften (Vol. 1, pp. 977-980). Hamburg: Meiner.

Salzmann, P. C. (2010). Methodology. In A. Barnard \& J. Spencer (Eds.), The Routledge encyclopedia of social and cultural anthropology (pp. 462-466). London: Routledge.

Schiaffonati, V. (2016). Stretching the traditional notion of experiment in computing: explorative experiments. Science and Engineering Ethics, 22, 647-665.

Scholz, O. R. (2009). Abbilder und Entwürfe: Bilder und die Strukturen der menschlichen Intentionalität. In K. Sachs-Hombach (Ed.), Bildtheorien: Anthropologische und kulturelle Grundlagen des Visualistic Turn (pp. 146-162). Frankfurt a. M: Suhrkamp.

Scholz, O. R. (2012). Bilder in Wissenschaften, Design und Technik: Grundlegende Formen und Funktionen. In D. Liebsch \& N. Mößner (Eds.), Visualisierung und Erkenntnis. Bildverstehen und Bildverwenden in Natur- und Geisteswissenschaften (pp. 43-57). Herbert von Halem Verlag: Köln.

Schön, D. A. (1983). The reflective practitioner: How professionals think in action. New York: Basic Books.

Schwab, M. (Ed.). (2014). Experimental systems: future knowledge in artistic research. Leuven: Leuven University Press.

Schwarte, L. (Ed. 2011). Experimentelle Ästhetik: VIII. Kongress der Deutschen Gesellschaft für Ästhetik 2011. Deutsche Gesellschaft für Ästhetik. http://www.dgae.de/kongress-akten-band-2.html. Accessed 22 May 2014.

Simon, H. A. (1969). The sciences of the artificial. Cambridge: MIT Press.

Vermaas, P. E., \& Dorst, K. (2007). On the conceptual framework of John Gero's FBS-model and the prescriptive aims of design methodology. Design Studies, 28, 133-157.

Vermaas, P. E., Kroes, P., Light, A., \& Moore, S. A. (Eds.). (2008). Philosophy and design: from engineering to architecture. Dordrecht: Springer.

Vincenti, W. G. (1990). What engineers know and how they know it: analytical studies from aeronautical history. Baltimore: Johns Hopkins University Press.

Winsberg, E. (2015). Computer simulations in science. In E. N. Zalta (Ed.), The Stanford encyclopedia of philosophy (Summer 2015 Edition). https://plato.stanford.edu/archives/sum2015/entries/simulationsscience/. Accessed 12 December 2016.

Yaneva, A. (2005). Scaling up and down: extraction trials in architectural design. Social Studies of Science, 35(6), 867-894.

Yaneva, A. (2009). The making of a building: a pragmatist approach to architecture. Bern: Peter Lang. 